DE82 015072

\title{
Apparatus for Dynamic Measurement of Gases Released from Materials Heated Under Programmed Temperature-Time Control
}

\author{
J. W. Early
}

R. M. Abernathey

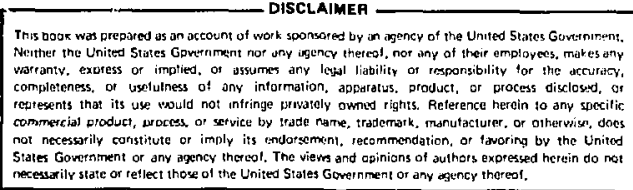

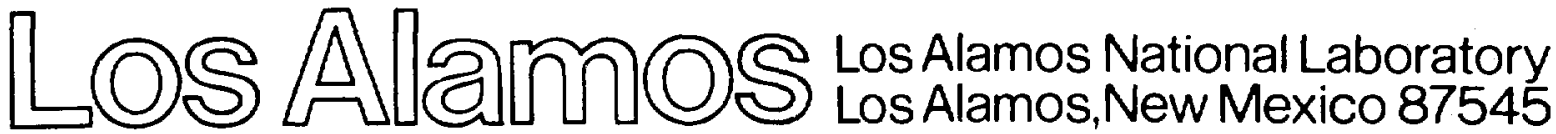




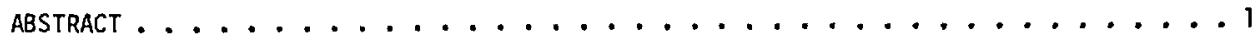

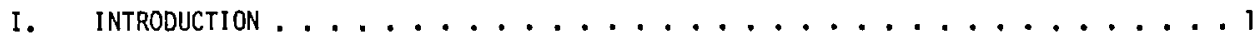

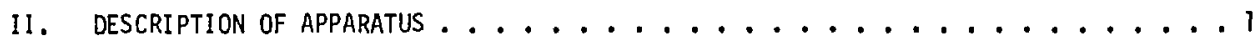

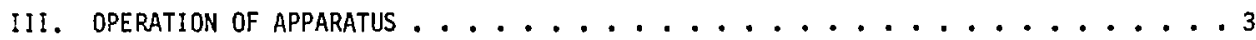

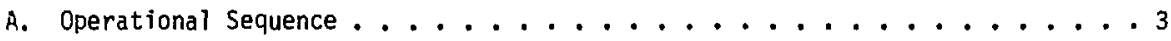

5. Data Recording and Treatment .................. 5

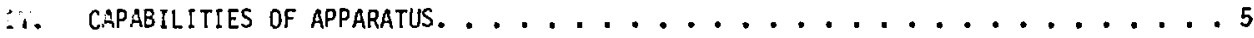

A. Measurement Range and Blank Values for Various Gases .......... 5

5. Establishment of Flow-Sensitivity factors. ............. 6

c. Limitations Caused by Reactions with Furnace Materials . . . . . . . 6

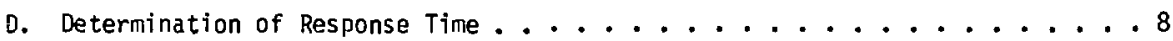

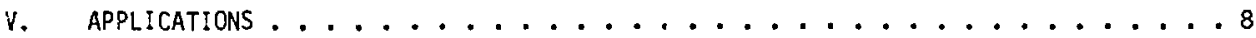

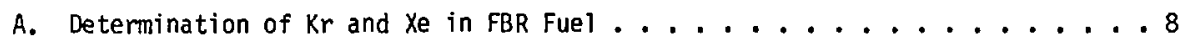

B. Determination of Gases Released from $\mathrm{UO}_{2}$ Pellets ........... 8

C. Determination of He Released from ${ }^{238} \mathrm{PuO}_{2}$ Power and Heat Sources ......9

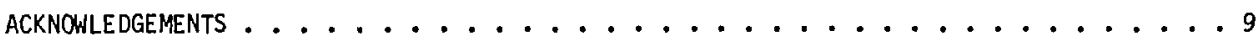

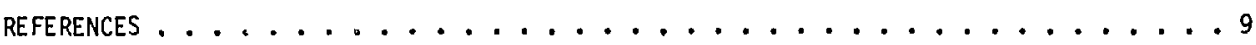

FIGURES

1. Glove box, quadrupole mass spectrometer, and data acquisition system . . . 2

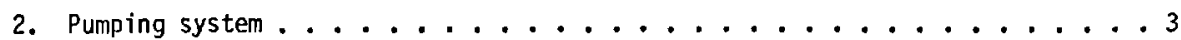

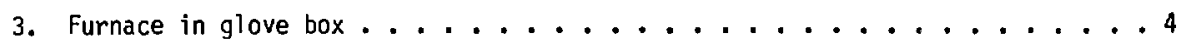

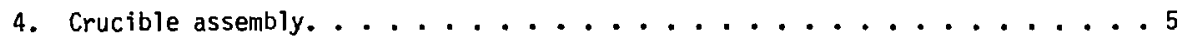

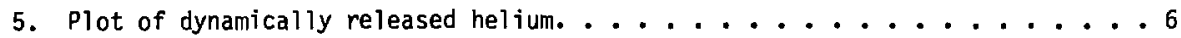

6. Reactions of oxygen, water, and methane with furnace .........8

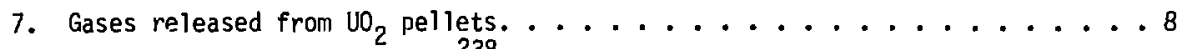

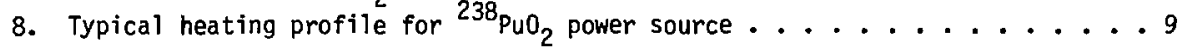

9. Plot of dynamically released helium from reentry heating profile ......

TABLES

I. Printed Output of Dynamically Released Helium. ............ 6

II. Typical Blank Values and Detection Limits. .............

III. Precision and Accuracy for He and $\mathrm{N}_{2} \ldots \ldots \ldots$ 


\section{APPARATUS FOR DYNAMIC MEASUREMENT OF GASES RELEASED FROM \\ MATERIALS HEATED UNDER PROGRAMMED TEMPERATURE-TIME CONTROL}

by

J. W. Early and R. M. Abernathey

\section{ABSTRACT}

This apparatus, a prototype of one being constructed for hotcell examination of irradiated nuclear materials, measures dynamic release rates and integrated volumes of individual gases from materials heated under controlled temperature-time programs. It consists of an inductively heated vacuum furnace connected to a quadrupole mass spectrometer. A computerized control system with data acquisition provides scanning rates down to $1 \mathrm{~s}$ and on-line tabular and graphic displays. Heating rates are up to $1300^{\circ} \mathrm{C} / \mathrm{min}$ to a maximum temperature of $2000^{\circ} \mathrm{C}$. The measurement range is about $10^{-6}$ to $10^{-2}$ torr-liter/s for $\mathrm{H}_{2}$, $\mathrm{CH}_{4}, \mathrm{H}_{2} \mathrm{O}, \mathrm{N}_{2}$, and $\mathrm{CO}$ and $10^{-8}$ to $10^{-2}$ torr-liter/s for $\mathrm{He}, \mathrm{Kr}$, and $\mathrm{Xe}$. Apolications are described for measurements of $\mathrm{Kr}$ and $\mathrm{Xe}$ in mixed oxide fuel, various gases in $\mathrm{UO}_{2}$ pellets, and He in ${ }^{238} \mathrm{PuO}_{2}$ power and heat sources.

\section{INTROOUCTION}

This apparatus was developed primarily as a prototype for hot-cell measurement of fission-product $\mathrm{Kr}$ and $\mathrm{Xe}$ and other gases reieased under controlled heating conditions from Fast Breeder Reactor (FBR) experimental fuels. Such measurements provide information concerning their gas-retention properties and irradiation stability.

This report presents a detailed description of the apparatus, its operational features, and experimental evaluations of its capability to neasure $\mathrm{Kr}$ and $x_{e}$ in FBR mixed oxide fuel, various impurity gases in $\mathrm{UO}_{2}$ pellets, and $\mathrm{He}$ in ${ }^{238} \mathrm{PuO}_{2}$ power and heat sources.

\section{DESCRIPTION OF APPARATUS}

The major components are (1) a vacuum furnace with vacuum locks for introduction and removal of samples, (2) a temperature-time programmer that controls an induction heater, (3) a vacuum pumping system, (4) a quadrupole mass spectrometer, and (5) an on-line data acquisition system. All components are commercial units except the furnace. Figure 1 shows the glovebox in which the furnace is located, the mass spectrometer, and the data acquisition system. Induction heating is provided by a Lepel 30-kW, 100kHz rf generator. A Datatrak, Model FGE 5110, programmer controls the generator. As shown in Fig. 2, the top and bottom vacuum locks of the furnace are evacuated by a $5-\mathrm{L} / \mathrm{s}$ diaphragm pump, a $60-\mathrm{L} / \mathrm{s}$ cryosorption pump, and a $25-\mathrm{L} / \mathrm{s}$ ion pump, used sequentially. These pumps are located directly below the furnace glove box and connect to the furnace vacuum locks with $1.5 \mathrm{~m}$ of 3.8 -cm-diam stainless steel piping. The UTI Model 100C quadrupole mass spectrometer and the furnace are evacuated by a $125-\mathrm{L} / \mathrm{s}$ turbomolecular pump. All pumps are oil-free to avoid hydrocarbon background.

The vertical furnace, shown in Fig. 3, provides gravity introduction and removal of samples through vacuum locks. The furnace is maintained continuously at a high vacuum to provide low and stable gas blanks and capability for high sample throughput rates.

The small furnace provides ease of operation and maintenance in a 91.4-cm $\times 91.4-\mathrm{cm} \times 61.0-\mathrm{cm}$ glove box. The furnace tube is fused quartz, $3.68-\mathrm{cm} 0 . d$. and 25.4-cm tall. A 2.75-in-o.d. Conflat flange is 


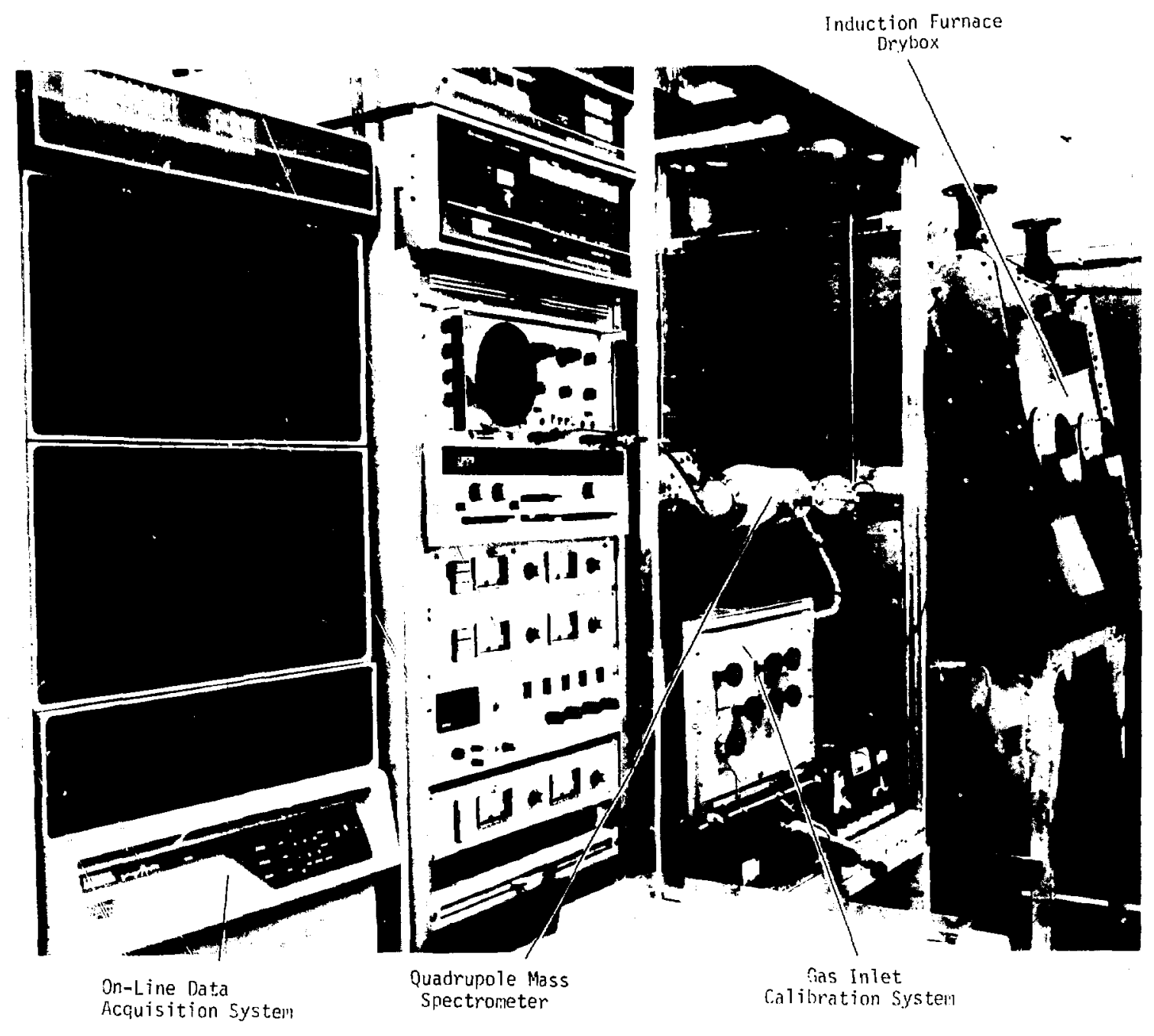

Fig. 1. Glove box, quadrupole mass spectrometer, and data acquisition system.

sealed to the tube at the top and bottom by double Vitron 0-rings with connections between them as a guard vacsum. The seals have proven leak-free after many thermal cycles of the furnace. The furnace assembly is sturdy and capable of withstanding maintenance handling. The conflat flanges are sealed rigidly to the top and bottom vacuum locks. The 0ring seals take up small expansions of the heated furnace tube and any vibrations. The furnace tube is cooled by water flowing in a polycarbonate encasement tube. The furnace is supported by four stainless steel tubes that are water cooled because of their close proximity to the 6-turn rf induction coil wrapped around the middle of the polycarbonate encasement tube.

Positioned at the center of the furnace tube is a 1.9-cm-0.d. and 15.2-cm-long tantulum crucible, shown in Fig. 4. The crucible is suspended freely from the upper vacuum lock to relieve thermal expansions. The vertical slots located directly above the lower portion of the crucible reduce the heat in this area induced by the $\mathrm{rf}$ field. The horizontal slot above the verical slots reduces the axial flow of heat to the crucible supports. 


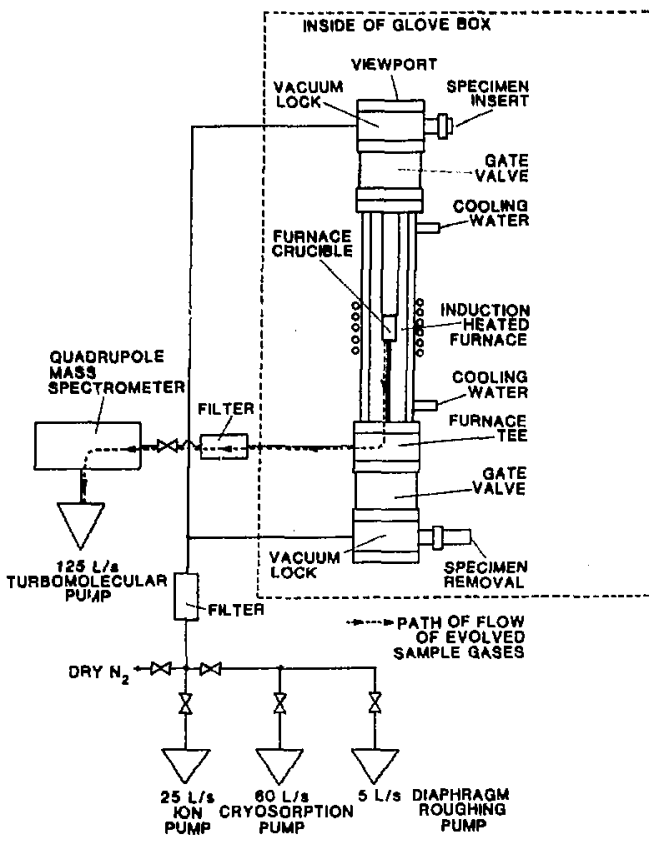

Fig. 2. Pumping System

The funnel portion of the crucible catches the introduced sample and guides it to rest on a hinged, tungsten trap door at the center point of the induction coil. The trap door is held closed by a tungsten rod connected to the gate valve of the lower vacuum lock. Manual opening of the gate valve results in opening the crucible trap door, allowing the expended sample to fall through the gate valve to a hopper in the lower vacuum lock.

The center hinge part of the trap door is fabricated from a rolled tantalum tab on the crucible. The hinge pin is a $1.5-\mathrm{mm}$-diam tungsten carbide rod that does not fuse to the refractory metal components during high-temperature operation. The trap door assembly has operated satisfactorily for hundreds of samples. For operation at $>1600^{\circ} \mathrm{C}$ with plutoniumcontaining samples, a $0.1-\mathrm{mm}$ tungsten liner is inserted into the crucible to prevent a plutoniumtantalum reaction.

The maximum sample size accepted is $\sim 1-\mathrm{cm}$ diam $x 1.6-\mathrm{cm}$ length. The apparatus easily handles FBR fuel and insulator pellets having usual dimensions of $0.62-\mathrm{cm}$ diam and $0.62-\mathrm{cm}$ length.

The vacuum locks have 0 -ring sealed ports at their sides through which samples are introduced or removed. Both locks have hoppers as sample receptacles. A trap door at the base of the upper hopper is linked mechanically to the vacuum-isolation gate valve. Opening the trap door allows the sample to drop into the furnace when the isolation valve is opened. The lower hopper is removed through the vacuum lock port to recover the expended sample. The gate valves on both upper and lower vacuum locks are actuated pneumatically to provide fast operation.

Line-of-sight of the furnace crucible is provided by a quartz window at the top vacuum lock. By optical pyrometry, the furnace is calibrated for temperature vs power setting to a repeatability of $4^{\circ} \mathrm{C}$ for the range of 1000 to $2000^{\circ} \mathrm{C}$.

Components in the apparatus are constructed of low-outgassing materials. Type 304 stainless stee 1 is used for most components and vacuum lines. Conflat copper gaskets are used except for Viton 0-ring Seals at the gate valves, quartz furnace tube, and vacuum lock ports.

A 2- $\mu$, high-flow, sintered stainless steel filter prevents passage of particles to the vacuum pumping system.

A Digital Equipment Corporation PDP-11/34 minicomputer system controls the quadrupole mass spectrometer, acquires on-line gas release data, and displays analytical results. The real-time minicomputer system consists of a central processor with 64-K words of memory, a dual RL01 hard disk-drive system capable of storing 2.5 million words, a fast 12-bit ADI1-K A/D converter for analog mass-peak height acquisition, a DLI1-K digital 1/0 interface for controlling the operation of the mass spectrometer, an LA-120 Decwriter terminal/printer that displays analytical results, and a KWll-K dual programmable clock for event timing. The on-line software is a timed task-swapping routine in which data acquisition and quadrupole mass spectrometer control are performed in an interrupt-driven manner. Data reduction, storage, and display are concurrent with data acquisition and mass spectrometer control events.

\section{OPERATION OF APPARATUS}

A. Operational Sequence

A blank is processed, using the same temperature-time program as sample(s), just prior to sample processing. 


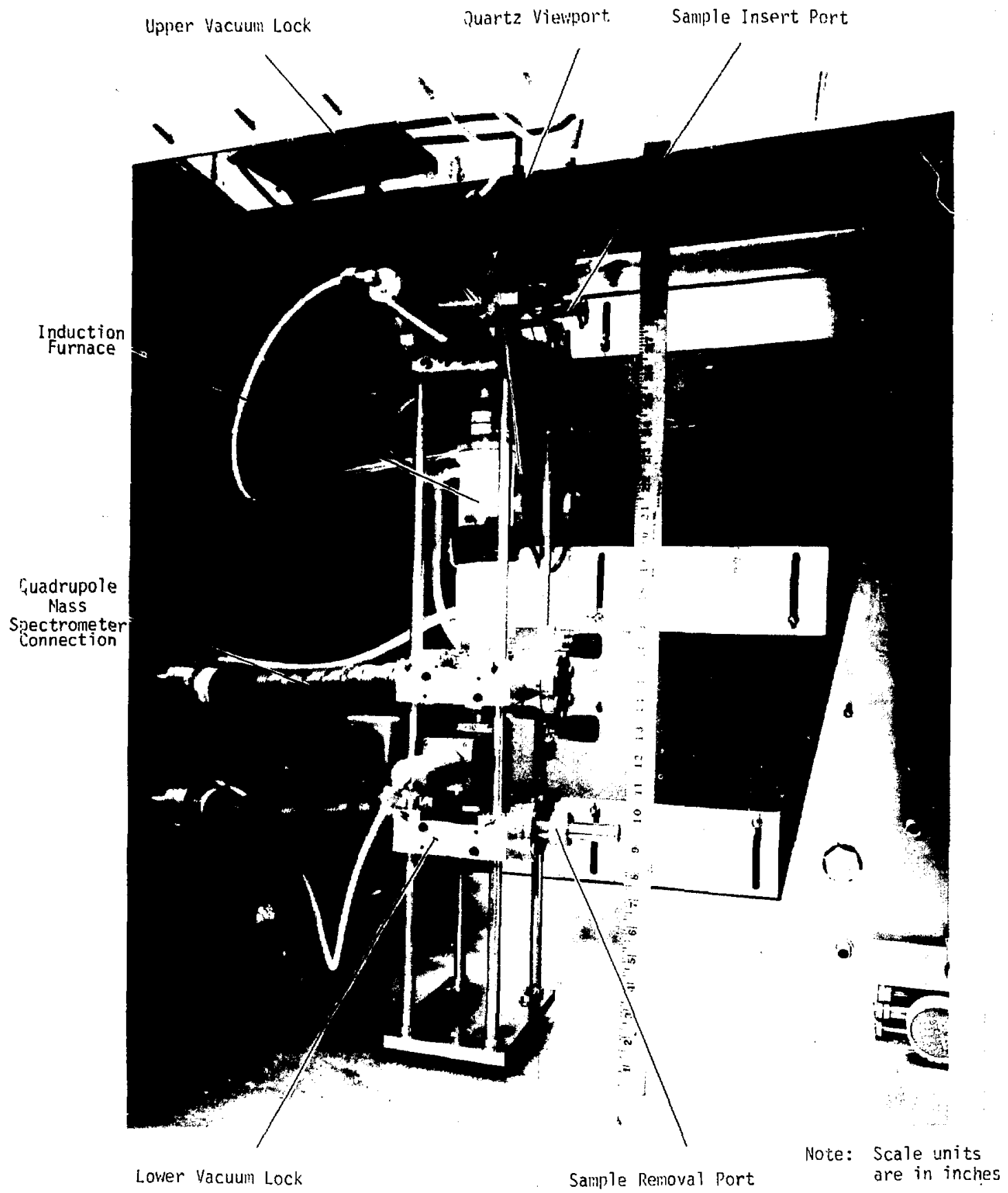

Fig 3. Furnace in glove box. 


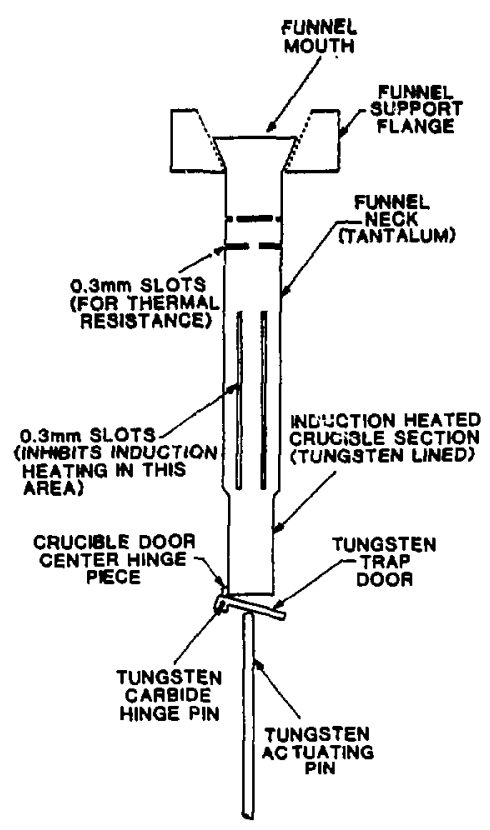

Fig. 4. Crucible assembly.

The general operationai sequence follows.

(a) Insert sample into upper vacuum lock.

(b) Pump down upper and lower vacuum locks.

(c) Drop sample into crucible by opening, then closing, the upper vacuum-lock isolation valve.

(d) Heat sample, using praset temperature-time program, under computer control. Start data acquisition.

(e) Drop sample from crucible by opening, then closing, lower vacuum lock.

(f) Pressurize vacuum locks with dry nitrogen to atmospheric pressure.

(g) Remove sample from lower vacuum lock. This step usually is done simultaneously with step (a) during the heating operation of a previously loaded sample.

A usual gas-release elapsed time is $1 \mathrm{~h}$ with a range of $2 \mathrm{~min}$ to $48 \mathrm{~h}$ depending on the information desired. The stability of the overall system is sufficiently high to provide reproducible blank data for $72 \mathrm{~h}$, thereby giving capability for a 24-h sample run preceded by a 24- $h$ blank and an optional 24-h blank afterwards. For gases, such as $\mathrm{He}$, that are not blank components, $48-h$ sample runs have been used.

The time required to pump down vacuum locks to $\leq 5 \mathrm{E}-6$ torr before insertion or removal of a sample is 15 to $25 \mathrm{~min}$. At $5 \mathrm{E}-6$ torr, opening the vacuum iocks does not affect the system blank significantly. A typical pumpdown sequence is operation of the diaphragm pump for 1 min to 10 torr, operation of the cryosorption pump for 15 min to $2 E-5$ torr, and operation of the ion pump for 5 min to $5 E-6$ torr.

\section{B. Data Recording and Treatment}

The mass spectrometer is programed to scan and measure release rates of desired gases at typica? intervals of 1 to $900 \mathrm{~S}$. The fastest scan rate is $2 \mathrm{amu} / \mathrm{s}, 1$ imited by the response of the detector's electrometer.

The blank values, taken just prior to samples, are subtracted point-by-point in elapsed time from the sample values. Also subtracted are mass spectrometer baseline values.

After completion of a sample scan, the blankcorrected dynamic-release rates in units of torr-L/s and integrated volume in units of STP $L$ for each gas are printed and graphed. Also printed are the accumulative (STP liter) volumes. Finally, the integrated volume of each gas is printed along with its computed volume percentage. A printed output and plot of a dynamic-release rate, of helium from a ${ }^{238} \mathrm{PuO}_{2}$ sample, are given in Table I and Fig. 5.

IV. CAPABILITIES OF AFPARATUS

A. Measurement Range and Blank Values for Various

\section{Gases}

The detection limit of the mass spectrometer generally is $1 \mathrm{E}-8$ torr-L/s for most gases, set by the noise level of the electron multiplier detector at the highest level of used amplifier gain. The blank levels of $\mathrm{H}_{2}, \mathrm{CH}_{4}, \mathrm{H}_{2} \mathrm{O}, \mathrm{N}_{2}$, and $\mathrm{CO}$ are above this detection limit. These gases are outgassed from various components in the furnace. Typical blank values of gases for a furnace-operating temperature range of 1400 to $1800^{\circ} \mathrm{C}$ are given in Table II. The variations in the blank values typically are $<5 \%$ over $24 \mathrm{~h}$. The overall detection 1 imits are taken as one-half the blank values as shown in Table II.

The maximum value measurable is about $\mathrm{IE}-2$ Torr $-L / s$ for the mass spectrometer used. Above this 
TABLE I

PRINTED OUTPUT OF DYNAMICALLY RELEASED HELIUM HELI LiT

$\begin{aligned} \text { HE RI:LEASE RUN ID } & =823 \\ \text { HE FLOW SENSITIVITY } & =3.106 \mathrm{E}-00004 \\ \text { HE RLN START BLOCK } & =03115 \\ \text { HE RUN END BLOCK } & =03117 \\ \text { HE BLANK START BLK } & =03107 \\ \text { RUN START TIME } & =16: 07: 16\end{aligned}$

\section{ACCUMULATED VALUES}

SCAN STP VOL (L)

2.190E-00011

1. $501 \mathrm{E}-00010$

3. $111 E-00010$

8.391E -00010

3. $199 E-00009$

2. $910 \mathrm{E}-00008$

2.90TE-00007

$1.407 \mathrm{E}-00006$

$2.757 \mathrm{E}-00006$

6.207E-00006

$8.217 E-00006$

1.041E-00005

1.264E-00005

]. $487 \mathrm{E}-00005$

$1.690 E-00005$

1. $860 \mathrm{E}-00005$

2. $008 E-00005$

2. $135 \mathrm{E}-00005$

2. $243 \mathrm{E}-00005$

2. $335 \mathrm{E}-00005$

2. $414 \mathrm{E}-00005$

$2.482 \mathrm{E}-00005$

2. $539 \mathrm{E}-00005$

2.588E-00005

2. $629 \mathrm{E}-00005$

$2.664 \mathrm{E}-00005$

2. $694 \mathrm{E}-00005$

2. $702 \mathrm{E}-00005$

2.742E-00005

2.760E-00005

$2.777 \mathrm{E}-00005$

2.792E -00005

2. $804 \mathrm{E}-00005$

2.815E-00005

2. 824E-00005

2.832E-00005

2. $838 \mathrm{E}-00005$

2. $844 E-00005$

2. $349 \mathrm{E}-00005$

2. $853 \mathrm{E}-00005$
4. $367 \mathrm{E}-00006$
CURRENT SCAN VALUES

\section{RELEASE RATE}

( $T-L / S$ )

1.93:JE-00003

$1.672 E-0 J 002$

2. $109 \mathrm{E}-00008$

6.922E-00008

3. $104 \mathrm{E}-00007$

3.366E-00006

3. 371E-00005

$1.427 \mathrm{E}-00004$

$1.774 \mathrm{E}-00004$

2. $087 \mathrm{E}-00004$

2. 375E-00004

$2.636 \mathrm{E}-00004$

2. $858 \mathrm{E}-00004$

2. $909 \mathrm{E}-00004$

2. $946 \mathrm{E}-00004$

2.599E-00004

2. 221E-00004

I. $899 \mathrm{E}-00004$

1. $623 \mathrm{E}-00004$

$1.384 \mathrm{E}-00004$

$1.181 \mathrm{E}-00004$

1. $008 \mathrm{E}-00004$

8.567E-00005

7.324E-00005

$6.256 \mathrm{E}-00005$

$5.336 \mathrm{E}-00005$

$3.859 \mathrm{E}-00005$

$3.285 \mathrm{E}-00005$

2.782E-00005

2. $348 \mathrm{E}-00005$

$2.172 \mathrm{E}-00005$

1. $855 \mathrm{E}-00005$

1. $586 \mathrm{E}-00005$

i. $357 \mathrm{E}-00005$

$1.757 E-00005$

$9.861 E-00006$

8.421E-00006

$7.178 \mathrm{E}-00006$

6.117E-00006

5. $194 \mathrm{E}-00006$

STP VOL (L) (SEC)

$2.190 \mathrm{E}-00011$

$1.232 \mathrm{E}-000107$

$1.610 \mathrm{E}-00010 \quad 13$

5.280E-00010 19

$2.360 \mathrm{E}-0000925$

$2.590 \mathrm{E}-0000830$

2.610E-00007 36

$1.117 \mathrm{E}-00006 \quad 42$

1.350E-00006 48

$1.840 \mathrm{E}-00006 \quad 60$

2.010E-00006 66

2.190E-00006 72

$2.230 E-0000677$

2.230E-00006 83

$2.030 \mathrm{E}-00006 \quad 89$

$1.480 \mathrm{E}-00006 \quad 101$

$1.277 \mathrm{E}-00006 \quad 107$

$1.076 \mathrm{E}-00006 \quad 113$

$9.280 \mathrm{E}-00007 \quad 119$

$7.880 \mathrm{E}-00007 \quad 125$

$6.730 E-00007 \quad 131$

$5.730 E-00007 \quad 137$

$4.880 E-00007 \quad 143$

$4.140 \mathrm{E}-00007 \quad 149$

3.5T $0 E-00007 \quad 154$

$3.030 \mathrm{E}-00007 \quad 160$

$2.550 \mathrm{E}-00007 \quad 166$

$2.180 \mathrm{E}-00007 \quad 172$

$1.840 E-00007 \quad 178$

I.700E $-00007 \quad 184$

$1.450 \mathrm{E}-00007 \quad 190$

$1.230 \mathrm{E}-00007 \quad 196$

$1.076 \mathrm{E}-00007202$

9.050E-00008 208

$7.730 \mathrm{E}-00008 \quad 214$

$6.650 \mathrm{E}-00008220$

5. 690E-00008 226

$4.760 \mathrm{E}-00008232$

4.030E-00008 238
4.542E-00005

$1.610 \mathrm{E}-00006 \quad 54$

$1.700 \mathrm{E}-00006 \quad 95$

flow rate, the flow-sensitivity factors decrease because of space-charge effects in the ionizer section.

\section{B. Establishment of Flow-Sensitivity Factors}

The flow-sensitivity factors are established

by flowing pure gases at known rates into the mass spectrometer operated at the conditions to be used

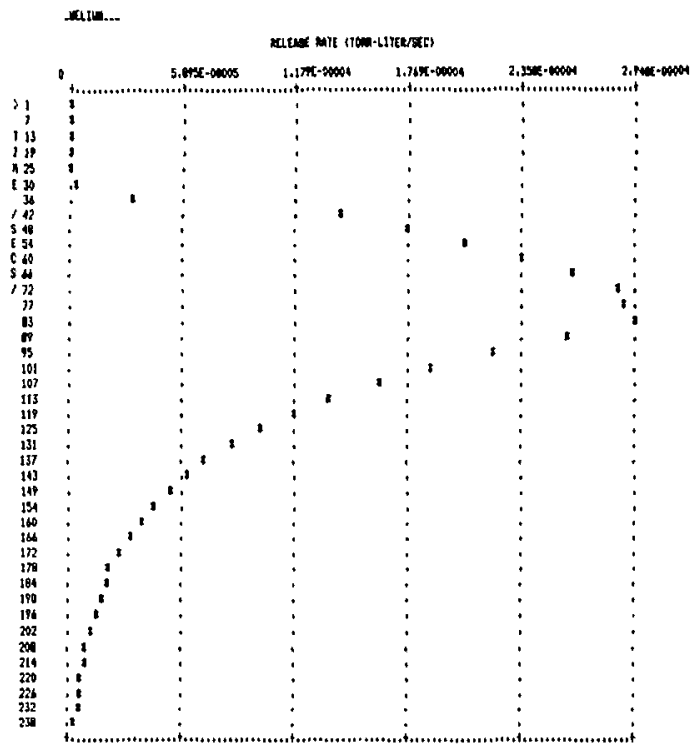

Fig. 5. Plot of dynamically released helium.

for samples (and blanks). The variations typically are less than $3 \%$ over $160 \mathrm{~h}$ of operating time. The evaluation of the overall reliability of the complete apparatus is difficult to establish. The best technique would be to heat well-characterized reference materials, especially those of the National Bureau of Standards (NBS). Unfortunately, the only NBS reference materials are metals that would melt and damage the furnace.

Reliability estimates were obtained by flowing $\mathrm{N}_{2}$ (a known blank component) and He (not detected in blanks) at rates from about 10 to 1000 times the detection limit for various elapsed times and comparing the measured integrated volumes to the input volumes (Table III). The precision (relative standard deviation) and biases were consistentiy $<2 \%$.

c. Limitations Caused by Reactions with Furnace Materials

A cironic problem associated with construction of furnaces used for gas-release measurements is reaction of furnace materials with various gases. For operation at temperatures to $2000^{\circ} \mathrm{C}$, there is no material that is mechanically stable and does not react with many gases present in nuclear fuels. Tantalum and tungsten were selected as the furnace component materials based on their mechanical stability and inertness to many gases. These two metals 
TABLE II

TYPICAL BLANK VALUES AND DETECTION LIMITS

Torr - L/S E- 6 at Temperature of

\begin{tabular}{|c|c|c|c|c|}
\hline Gas & $1400^{\circ} \mathrm{C}$ & $1600^{\circ} \mathrm{C}$ & $1800^{\circ} \mathrm{C}$ & (Torr-L/s) at $1800^{\circ} \mathrm{C}$ \\
\hline $\mathrm{H}_{2}$ & 0.60 & 0.80 & 1.6 & $8 E-7$ \\
\hline $\mathrm{He}$ & $<0.1$ & $<0.1$ & $<0.1$ & $<5 E-8$ \\
\hline $\mathrm{CH}_{4}$ & $<0.1$ & $<0.1$ & $<0.1$ & $<5 \mathrm{E}-8$ \\
\hline $\mathrm{H}_{2} \mathrm{O}$ & 0.15 & 0.17 & 0.17 & $9 E-8$ \\
\hline CO & 0.80 & 1.0 & 1.3 & $7 E-7$ \\
\hline$N_{2}(a)$ & $<0.1$ & 0.16 & 0.16 & $8 E-8$ \\
\hline$k r$ & $<0.1$ & $<0.1$ & $<0.1$ & $<5 E-8$ \\
\hline$x e$ & $<0.1$ & $<0.1$ & $<0.1$ & $<5 \mathrm{E}-8$ \\
\hline
\end{tabular}

(a) At the detection limit, $\mathrm{N}_{2}$ and $\mathrm{CO}$ are indistinguishable

TABLE III

PRECISION AND ACCURACY FOR HE AND $\mathrm{N}_{2}$

\begin{tabular}{|c|c|c|c|c|c|c|}
\hline Gas & $\begin{array}{l}\text { Av Flow } \\
\text { Torr-L/S }\end{array}$ & $\begin{array}{r}\text { Input } \mathrm{Vol}^{\mathrm{Std} \mathrm{cm}^{3}} \\
\end{array}$ & $\begin{array}{l}\text { Measured Vot, } \\
\text { Std } \mathrm{cm}^{3}\end{array}$ & $\begin{array}{l}\text { Number } \\
\text { of Tests }\end{array}$ & $\begin{array}{l}\text { Std Dev, } \\
\text { Rel \% }\end{array}$ & $\begin{array}{l}\text { Av } \\
\text { Bias, \% }\end{array}$ \\
\hline $\mathrm{He}$ & $2.6 \mathrm{E}-7$ & 7.07 E-5 & 6.92 E-5 & 5 & 1.8 & -2.1 \\
\hline $\mathrm{He}$ & $2.7 \mathrm{E}-6$ & $7.07 \mathrm{E}-4$ & $7.04 E-4$ & 4 & 0.6 & -0.4 \\
\hline He & $1.8 \mathrm{E}-5$ & $7.07 \mathrm{E}-3$ & $7.02 E-3$ & 4 & 0.8 & -0.7 \\
\hline $\mathrm{He}$ & $1.7 \mathrm{E}-4$ & $7.07 \mathrm{E}-2$ & $7.05 \mathrm{E}-2$ & 4 & 1.5 & -0.3 \\
\hline$N_{2}$ & $7.1 \mathrm{E}-7$ & $3.54 \mathrm{E}-4$ & $3.46 E-4$ & 4 & 0.5 & -2.2 \\
\hline $\mathrm{N}_{2}$ & $7.7 \mathrm{E}-6$ & $3.54 \mathrm{E}-3$ & $3.61 \mathrm{E}-3$ & 4 & 1.0 & +2.0 \\
\hline $\mathrm{N}_{2}$ & $7.9 E-5$ & $3.54 \mathrm{E}-2$ & $3.56 \mathrm{E}-2$ & 4 & 0.7 & +0.6 \\
\hline
\end{tabular}

react with $\mathrm{O}_{2}$ to form oxides, with $\mathrm{H}_{2} \mathrm{O}$ to form oxides and $\mathrm{H}_{2}$, and with $\mathrm{CH}_{4}$ to form carbides and $\mathrm{H}_{2}{ }^{1-3}$ The reactions are dependent on temperature and surface condition of the metals in a complex manner. Correction for these reactions is, therefore, difficult. The extents of the reactions of $\mathrm{O}_{2}, \mathrm{CH}_{4}$, and $\mathrm{H}_{2} \mathrm{O}$ were measured for the furnace starting with clean metal surfaces. The three gases were introduced individually into the furnace at known rates over a temperature range of 25 to $1800^{\circ} \mathrm{C}$. The fraction of gas thac reacted was computed based on the rate measured by the mass spectrometer. As shown in
Fig. 6, the reaction order is $\mathrm{O}_{2}>\mathrm{H}_{2} \mathrm{O}>\mathrm{CH}_{4}$. This, then, also is the measurement uncertainty order for samples. Because the reaction of $\mathrm{H}_{2} \mathrm{O}$ and $\mathrm{CH}_{4}$ with tantalum and tungsten produces $\mathrm{H}_{2}$, measurement of $\mathrm{H}_{2}$ also is uncertain when these gases are present. Because the reactions are dependent on surface conditions of the metal componerts, corrections require calibrations just prior to and just after sample processing. Extensive experimentation to establish the reliability of such corrections has not been done. With clean metal surfaces, the reaction rates shown in Fig. 6 were reproducible to $\pm 10 \%$. 


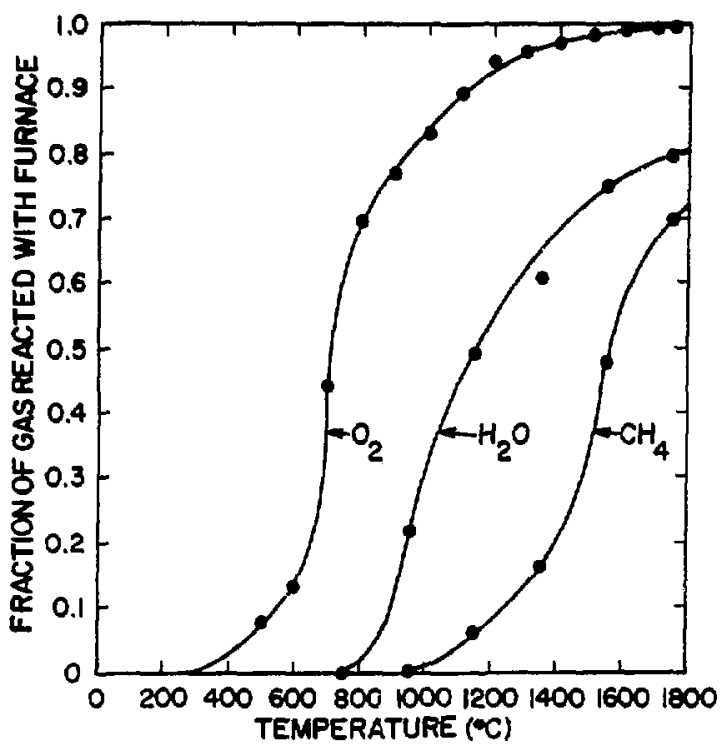

Fig. 6. Reactions of oxygen, water, and methane with furnace.

\section{Determination of Response Time}

To minimize constriction effects, all vacuum piping and particle-entrainment filters were fabricated to have high conductance. To demonstrate the effectiveness of the apparatus to measure dynamically a. sudden gas release, a known flow of $\mathrm{N}_{2}$ was introduced suddenly into the furnace. The elapsed time between the release of the $\mathrm{N}_{2}$ and its detection at the quadrupole mass spectrometer was less than $1 \mathrm{~s}$ at a flow rate of $\mathrm{IE}-6$ torr-L/s. This response, comparable to the fastest scan rate of the spectrometer, is acceptable.

\section{v. APPLICATIONS}

A. Determination of $\mathrm{Kr}$ and $\mathrm{Xe}$ in FBR Fuel

Experiments with the prototype have shown that

$\mathrm{Kr}$ and $\mathrm{xe}$ isotopes are measured with ample sensitivity for application to retained-gas analysis of FCR fuel. 4 The low-abundance fission-yield isotopes ${ }^{84} \mathrm{Kr}$ and ${ }^{131}$ Ye were measured with ample sensitivity to determine $10 \%$ retained $\mathrm{Kr}$ and $\mathrm{Xe}$ in $1 \mathrm{~g}$ of $\mathrm{Pu}$ having $1 \%$ burnup. The integrated volumes measured for constant rate flows over a 1.5-h elapsed time were $3 \mathrm{E}-4 \mathrm{std} \mathrm{cm}^{3}$ of ${ }^{84} \mathrm{Kr}$ and $3.5 \mathrm{E}-3$ std $\mathrm{cm}^{3}$ of ${ }^{131} \mathrm{Xe}$. For FBR mixed oxide fuel, the quantity of $84 \mathrm{Kr}$ will be greater.
B. Determination of Gases Released from $\mathrm{UO}_{2}$ Pellets

Pellets of $\mathrm{UO}_{2}$ from a batch that had been prepared by calcination of uranium oxide with a carbowax binder at $1600^{\circ} \mathrm{C}$ in a steam- $\mathrm{H}_{2}$ atmosphere were processed. Four pellets were processed at $1400^{\circ} \mathrm{C}$, four at $1600^{\circ} \mathrm{C}$, and three at $1300^{\circ} \mathrm{C}$. The elapsed time for $>99 \%$ release of all gases was 1 to $1.5 \mathrm{~h}$. The measured integrated quantities of $\mathrm{H}_{2}, \mathrm{H}_{2} \mathrm{O}, \mathrm{CH}_{4}, \mathrm{CO}$, and $\mathrm{N}_{2}$ are plotted in Fig. 7. The standard deviations are represented by error bars. Pure gases were not processed through the furnace to enable corrections with furnace components. Therefore, the data represent the combinations of released gases and their reactions.

The increase in $\mathrm{CO}$ with increase in temperature is attributed to its formation by reaction of residual carbonaceous matter with $\mathrm{UO}_{2}, \mathrm{C}+2 \mathrm{UO}_{2} \rightarrow \mathrm{CO}+$ $\mathrm{U}_{2} \mathrm{O}_{3}$. Another mode of formation may be reaction of $\mathrm{CH}_{4}$ with $\mathrm{UO}_{2}, \mathrm{CH}_{4}+6 \mathrm{UO}_{2} \longrightarrow \mathrm{CO}+3 \mathrm{U}_{2} \mathrm{O}_{3}+2 \mathrm{H}_{2} \mathrm{O}$, indicated by the decrease in $\mathrm{CH}_{4}$ and increase in $\mathrm{H}_{2} \mathrm{O}$ with increasing temperature. Undoubtedly, the

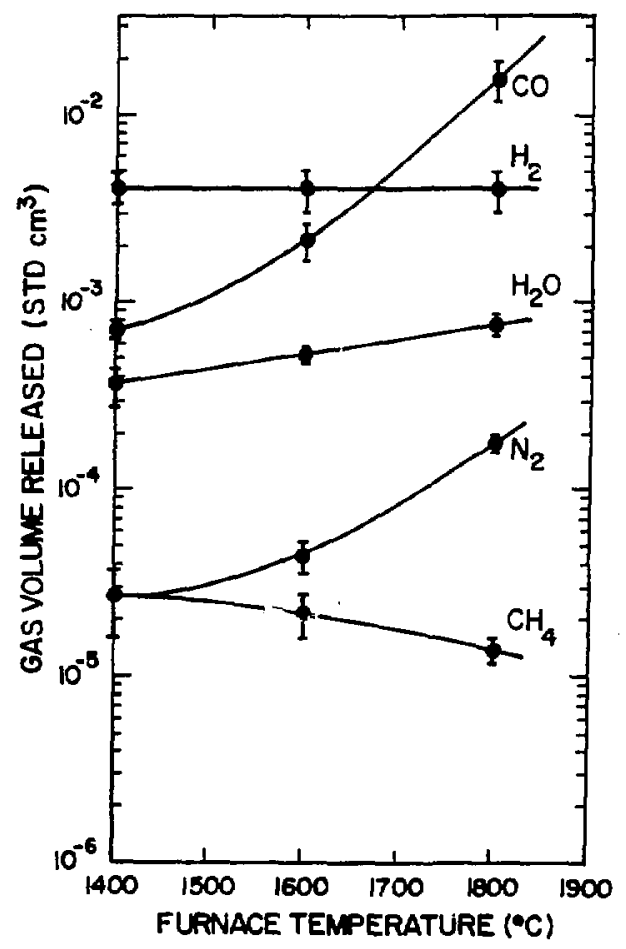

Fíg. 7. Gases released from $\mathrm{UO}_{2}$ pellets. 
released $\mathrm{H}_{2} \mathrm{O}$ reacts with metal components of the furnace to produce $\mathrm{H}_{2}$. However, the amount of $\mathrm{H}_{2}$ formed by this reaction is small relative to the amount of $\mathrm{H}_{2}$ initially present in the pellets. The low amount of $\mathrm{N}_{2}$ released is evidence of low amounts of air in the pellets. The apparent increase in $\mathrm{N}_{2}$ released with increasing temperature, which parallels the co release, probably reflects imperfect cracking-pattern factors for equal mass $\mathrm{CO}$ and $\mathrm{N}_{2}$. C. Determination of He Released from ${ }^{238} \mathrm{PuO}_{2}$ Power and Heat Sources

The applicability of the apparatus to measure $\mathrm{He}$, the alpha-decay product of plutonium and uranium isotopes, was demonstrated initially on a batch of FBR mixed-oxide fuel pellets. Seven 5-yr-uld pellets were processed at $1800^{\circ} \mathrm{C}$. The integrated amounts of helium released ranged from 0.0023 to $0.0032 \mathrm{std} \mathrm{cm}^{3} / \mathrm{g}$.

The apparatus was used to measure the $\mathrm{He}$ released from a large number of ${ }^{238} \mathrm{PuO}_{2}$ space power and heat sources using a variety of heating conditions. Heating rates ranged from $10^{\circ} \mathrm{C} / \mathrm{min}$ to $1300^{\circ} \mathrm{C} /$ min for elapsed times of 2 min to $48 \mathrm{~h}$. A typical heating profile that simulates the temperature change undergone upon atmosphere reentry is given in Fig. 8. The dynamic plot of the release for this heating mode is shown in Fig. g. To ensure total release of $\mathrm{He}$, the programed heating is ended with an isothermal heating at 1600 to $1800^{\circ} \mathrm{C}$ until the He release decreases to insignificance.

The quantity of ${ }^{238} \mathrm{PuO}_{2}$ processed ranged from 0.04 to $3 \mathrm{~g}$. The total amount of He released ranged from 0.009 to $4 \mathrm{std} \mathrm{cm}^{3}$. The measured total released He has agreed closely and consistently with the He calculated from radioactive decay.

\section{ACKNOWLEDGEMENTS}

J. S. Starzynsky provided temperature calibrations of the furnace. D. E. Hull and coworkers provided control instrumentation for the $r f$ generator. J. E. Rein provided initial editing.

\section{REFERENCES}

1. E. Fromm and H. Jehn, "Reactions of Niobium and Tantalum with Gases at High Temperatures and Low Pressures," Vacuum 19, 19i-197 (1969).

2. M. Kilpatrick and S. Lott, "Reactions of Flowing Steam with the Refractory Metals Niobium and

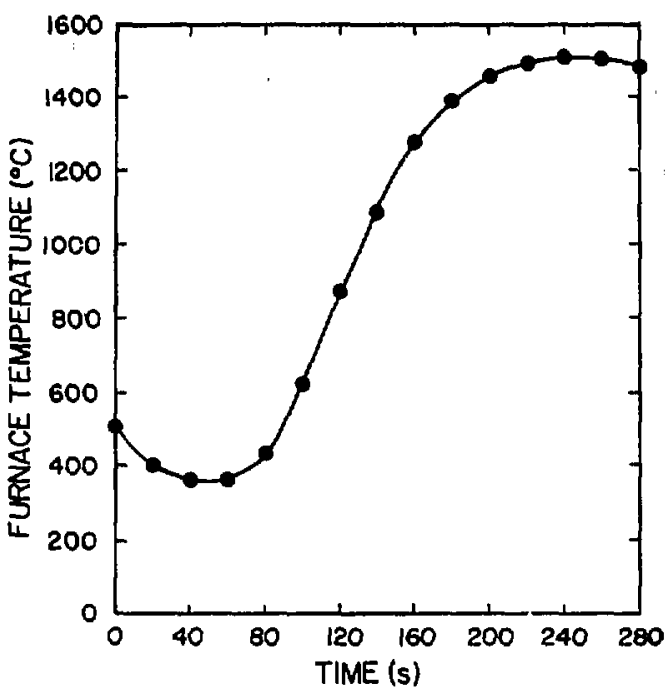

Fig. 8. Typical heating profile for ${ }^{238} \mathrm{PuO}_{2}$ power source.

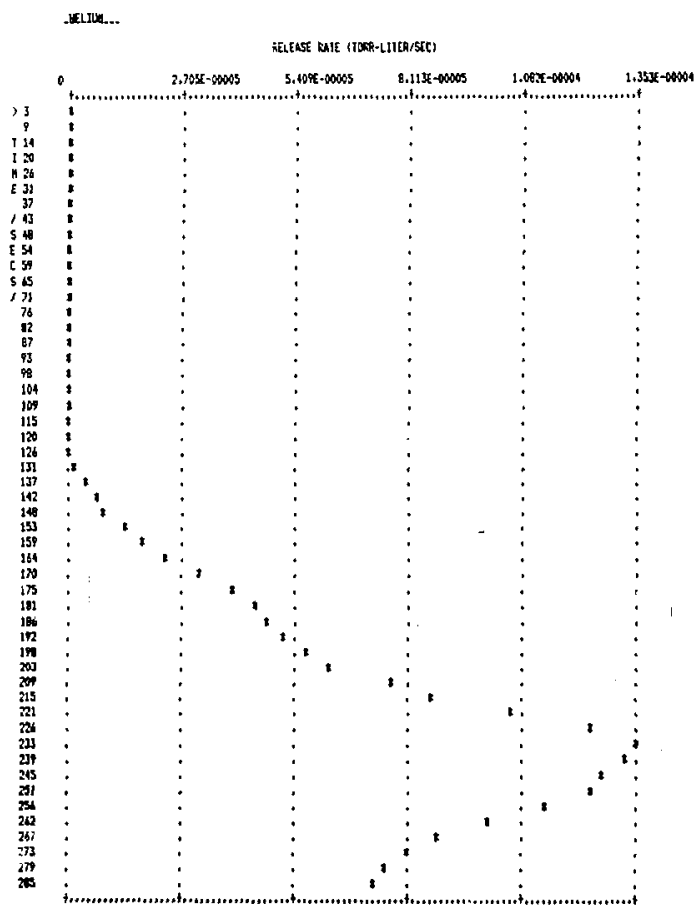

Fig. 9. Plot of dynamically released helium from reentry heating profile. 
Tantalum," J. Less Common Metals $8,299-305$ (1965).

3. E. Fromm, "Gas-Metal Reactions of Reŕractory Metals at High Teniperatures in High Vacuunr,"

J. Vac, Sci. Technol. 6, 100-105 (1970).
4. W. J. Maraman, "Examination of Fast Reactor Fuels and FBR Analytical quality Assurance Standards and Methods, July 1 - September 30, 1980," LOS Alamos Scientific Laboratory report LA-8623PR (December 1980). 